Etnográfica

Revista do Centro em Rede de Investigação em

Antropologia

vol. 14 (2) | 2010

Vol. $14(2)$

\title{
Banglapara: imigração, negócios e (in)formalidades
} em Lisboa

Banglapara: immigration, businesses and (in)formalities in Lisbon

José Mapril

\section{(2) OpenEdition}

Journals

Edição electrónica

URL: https://journals.openedition.org/etnografica/284

DOI: 10.4000/etnografica.284

ISSN: 2182-2891

\section{Editora}

Centro em Rede de Investigação em Antropologia

Edição impressa

Data de publição: 1 junho 2010

Paginação: 243-263

ISSN: 0873-6561

\section{Refêrencia eletrónica}

José Mapril, «Banglapara: imigração, negócios e (in)formalidades em Lisboa», Etnográfica [Online], vol. 14 (2) | 2010, posto online no dia 21 outubro 2011, consultado o 10 fevereiro 2022. URL: http:// journals.openedition.org/etnografica/284 ; DOI: https://doi.org/10.4000/etnografica.284

\section{(c) (i) (9)}

Etnográfica is licensed under a Creative Commons Attribution-NonCommercial 4.0 International License. 


\title{
Banglapara: imigração, negócios e (in)formalidades em Lisboa ${ }^{1}$
}

\section{José Mapril}

\begin{abstract}
Nos últimos anos, os estudos sobre migrações têm atribuído uma crescente importância aos negócios e às actividades empresariais. A existência de oportunidades estruturais e a disponibilidade de capital social são duas dimensões frequentemente mencionadas para explicar a sua emergência. Uma terceira dimensão remete para a relação entre imigração e as chamadas economias subterrâneas, paralelas ou informais. É precisamente este o tema que o presente artigo pretende abordar. Baseado num estudo de caso sobre as actividades empresariais desenvolvidas por imigrantes oriundos do Bangladeche, em Lisboa, este artigo pretende mostrar que o êxito de muitas das suas actividades depende, directamente, do recurso a estratégias que se encontram entre o formal e o informal.
\end{abstract}

PALAVRAS-CHAVE: informalidade, empresários, imigração, Lisboa, bangladechianos, Europa do Sul.

COM BASE NUM TRABALHO DE CAMPO REALIZADO ENTRE 2003 E 2006, este artigo pretende descrever os negócios desenvolvidos pelos migrantes oriundos do Bangladeche em Lisboa. Este exercício etnográfico permite constatar que muitas destas iniciativas envolvem algumas práticas que, de acordo com os modelos normativos da economia, se encontram na economia dita "subterrânea", "paralela" ou "informal". Por informalidade refiro-me, inspirado na definição de Keith Hart (1973), a um continuum de acções sociais que vão desde práticas económicas não reguladas, num ambiente onde estas o costumam ser,

l Gostaria de agradecer o apoio da Fundação para a Ciência e a Tecnologia, através da bolsa SFRH/BD/13237/2003, sem a qual toda esta pesquisa teria sido impossível. Uma primeira versão deste texto foi apresentada na VIII Conferência da European Association of Social Anthropologists. Agradeço as leituras e sugestões de Marzia Grassi, de Nuno Dias e dos dois referees anónimos que em muito contribuíram para a reformulação da primeira versão deste texto. Todas as incorrecções são, obviamente, da minha exclusiva responsabilidade. 
até actividades frequentemente categorizadas como ilegais. ${ }^{2} \mathrm{O}$ objectivo central deste artigo é pois mostrar como muitos dos meus interlocutores desenvolvem as suas actividades entre a economia formal e a informal e o que isto nos diz acerca da relação entre imigração e empresarialidade.

$\mathrm{Na}$ literatura sobre migrações, estes temas têm sido tratados nas abordagens à comummente designada empresarialidade imigrante ou étnica. Estes conceitos, oriundos da economia do desenvolvimento e da sociologia económica e das migrações, pretendem mostrar que a participação das populações imigrantes nos mercados de trabalho está muito para além do binómio assimilação/exclusão. Os imigrantes não tendem a diluir-se na sociedade de acolhimento através de um processo de mobilidade social crescente e assimilação, mas também não se encontram inevitavelmente numa situação permanente de exploração e de inferioridade no mercado de trabalho. Usando termos como integração, inserção, modos de incorporação e inclusão, vários autores têm mostrado que existem modos alternativos de participação nos mercados de trabalho, e a corroborá-lo estão os exemplos dos coreanos em Los Angeles, dos cubanos em Miami, dos chineses em Nova Iorque, dos paquistaneses em Manchester, ou mesmo dos indianos em Londres.

Em Portugal, nos últimos anos, surgiu um crescente número de contributos que, influenciados por estas perspectivas teóricas, se propõem interpretar a inserção laboral dos migrantes. Abordando casos entre os cabo-verdianos, os chineses e os indianos (hindus e muçulmanos), autores como Marques, Santos e Araújo (2001), Marques e Dias (2005), Grassi (2003), Oliveira (2005), Malheiros (2001), Góis (2006), entre outros, procuram mostrar como a participação dos migrantes nos mercados de trabalho em Portugal não se

2 A informalidade foi um conceito inicialmente proposto por Keith Hart num artigo publicado em 1973 sobre as actividades económicas que encontrou em Nima, nos arredores de Acra, no Gana. Hart sugeriu que as actividades informais contemplam práticas, simultaneamente legítimas e ilegítimas, de obtenção de rendimento. Por legítimas e ilegítimas o autor refere-se a actividades irregulares e ilegais, respectivamente, e que vão da agricultura e da construção civil não taxadas até ao tráfico de droga e à corrupção. Tal definição apresenta-se em forte contraste com propostas posteriores, tais como a de Portes (1999), para quem a economia informal se define como a soma de todas as actividades que geram rendimento sem serem reguladas por códigos legais, num ambiente em que essas actividades o são. Segundo tal perspectiva, as actividades informais distinguem-se das criminais porque envolvem bens e serviços legais; apenas a produção e a distribuição carecem de regulação. Tal distinção, no entanto, parece-me heuristicamente problemática, precisamente porque, como Cunha (2006) argumenta, as fronteiras entre actividades criminais e apenas irregulares é tão fluida que, em certo sentido, tal distinção parece perder muito do seu interesse analítico. Uma outra perspectiva advoga que deveremos deixar de falar de informalidade, já que esta é, antes de mais, uma construção social de cariz normativo usada para produzir alteridade. No entanto, e ainda que o argumento pareça razoável, a consequência imediata é que torna estes processos de marginalização invisíveis. Mais uma vez recorro a Cunha (2006) para argumentar que a dicotomia formal/informal parece ser um instrumento útil, ainda que imperfeito, para iluminar estes processos e dinâmicas de marginalização (para mais desenvolvimentos sobre a informalidade, $v d$. Portes e Castells 1989; Sassen 1998; Grassi 2003; Cunha 2006). 
caracteriza apenas por uma persistente situação de exclusão e marginalidade visível na ocupação de posições desprivilegiadas nos sectores laborais (Baganha, Malheiros e Ferrão 1999; Machado 2002). Existem casos que revelam estratégias alternativas que passam pelo empreendedorismo e pela inovação.

Nos discursos políticos, tais casos são frequentemente celebrados como exemplos do bom e exemplar imigrante que, depois de muito esforço e empenho, conseguiu montar um negócio e ser hoje o seu próprio patrão. Criou a sua própria oportunidade e ajudou outros no processo. Mais, eles são vistos como os bons imigrantes, pois vão ao encontro dos modelos hegemónicos da economia, em que o empreendedor é o motor de todo o sistema económico.

No entanto, importa perceber que estas iniciativas têm um lado menos visível, mais nocturno. Segundo Bonacich (1993), este lado está relacionado com processos de marginalização social, que são frequentemente silenciados nos discursos normativos. Desde logo, não é de todo raro muitas destas iniciativas empresariais resultarem de processos de discriminação racial, étnico-nacional, de género, entre outras. Não conseguindo aceder ao mercado de trabalho nas condições desejadas, a única possibilidade é desenvolver negócios por conta própria ( $v d$. ., entre outros, Bonacich 1987, 1993; Oliveira e Rath 2008). Para muitos, estes negócios são vistos como a única oportunidade de mobilidade social ascendente num contexto marcado por vários bloqueamentos estruturais.

Mas a relação entre estes negócios e dinâmicas de marginalização ocorre mesmo no desenvolvimento da própria prática empresarial. Muitos empresários apenas conseguem desenvolver actividades nas margens da economia, e como tal enfrentam frequentemente enormes dificuldades económicas. Num tal cenário, recorrem a estratégias de natureza informal, sem as quais tais iniciativas estariam inevitavelmente destinadas ao fracasso (Rath 2000). Para clarificar este argumento, sugiro que pensemos na proposta teórica do chamado "encastramento misto" (Kloosterman, Van der Leun e Rath 1999; Kloosterman e Rath 2001). Para explicar a emergência do empreendedorismo imigrante, estes autores mencionam o duplo encastramento de muitas destas iniciativas. Por um lado, refere-se a relação entre a emergência e o tipo de negócios desenvolvidos e as oportunidades estruturais existentes nos vários países. Por oportunidades estruturais entende-se o contexto político institucional (programas de incentivo, regulação, etc.) e os mercados (abandonados, desejados, em crescimento, etc.), a nível local, regional e mesmo nacional, que determinam, até certo ponto, as actividades empresariais desenvolvidas. Por outro lado, alude-se ao encastramento destas iniciativas nas redes sociais, muitas vezes referidas como étnicas, ${ }^{3}$ e ao capital social a que estas permitem aceder e que é indispensável para os investimentos a realizar. Seria através deste encastramento misto que se poderia explicar não apenas a emergência

3 Para uma crítica à relação entre etnicidade, negócios e redes sociais, vd. Marques e Dias (2005). 
de muitas destas iniciativas, mas também, e ao mesmo tempo, as muitas diferenças existentes entre países, regiões e mesmo cidades.

Ora, é precisamente o lado da estrutura de oportunidades desenvolvido neste modelo que nos permite perceber a relação com a informalidade. Muitos empresários imigrantes apenas conseguem desenvolver as suas actividades através da apropriação e ocupação dos espaços mais desvalorizados da estrutura de oportunidades, ou seja, em mercados pouco exigentes em termos de capital económico e educacional. O lado positivo destes mercados é permitirem uma fácil instalação, o que é contrabalançado por uma enorme competição, que reduz drasticamente os rendimentos. Em face disto, muitos destes pequenos empresários são forçados a desenvolver actividades que frequentemente se encontram nos interstícios da formalidade e sem as quais muitas destas iniciativas não conseguiriam sobreviver. Assim, poder-se-ia argumentar que o recurso a estratégias económicas descritas como informais, nas visões normativas da economia, resulta da própria marginalização, que "empurra" determinadas populações para certos lugares no mercado de trabalho. Assim, e em linha com o argumento de Bonacich (1987), temos de ser cautelosos na forma como interpretamos muitas destas iniciativas empresariais, já que a sua celebração pode ter como efeito indesejado silenciar formas de exclusão e marginalização.

O caso dos bangladechianos em Lisboa é um bom exemplo para explorar etnograficamente muitas destas ambiguidades. Para tal, começarei por descrever a Praça Martim Moniz, em Lisboa, onde muitos dos meus interlocutores se têm estabelecido comercialmente nas últimas duas décadas. Seguidamente, mostrarei a interligação entre os aspectos formais e informais nas suas práticas comerciais e, finalmente, nas conclusões, voltarei a questões mais gerais sobre a relação entre informalidade e imigração, recorrendo a algum material comparativo.

\section{UMA BANGLAPARA EM LISBOA}

Os bangladechianos que chegaram entre o final dos anos 80 do século XX e 1996 começaram por trabalhar nos sectores mais desprivilegiados da economia portuguesa, principalmente como varredores, pintores de construção civil, pedreiros, capatazes, cozinheiros e vendedores ambulantes. ${ }^{4}$ Hoje são os proprietários de vários negócios em Lisboa, no Porto e no Algarve. ${ }^{5}$

4 Este percurso profissional está relacionado com o próprio estatuto legal. Muitos deslocaram-se a Portugal com o intuito de se legalizar através dos processos de regularização extraordinária (desenvolvidos nos anos 90 e em 2001). Enquanto aguardavam a resolução dos seus processos e perante a necessidade de fazer face às despesas quotidianas e processuais, procuraram ter acesso ao mercado de trabalho nos "lugares" possíveis, isto é, nos sectores mais desvalorizados e nos quais a informalidade tem uma grande importância (venda ambulante, construção civil, entre outros). Após a legalização, envidaram esforços para criar pequenos negócios.

5 Apesar destas trajectórias ascendentes, aqueles que chegaram nos últimos anos [continua] 
Por detrás de tais estratégias encontramos um conjunto alargado de motivações e factores que importa sublinhar. Em primeiro lugar, e de acordo com alguns dos meus interlocutores, um dos principais factores que os levaram a investir num negócio por conta própria estava relacionado com os reduzidos salários; trabalhando para outrem (conterrâneos ou não), os ordenados eram excessivamente baixos para conseguir pagar as despesas fixas, as despesas diárias e poupar para enviar para o Bangladeche. A acumulação de capital, a fazer-se, implicava longos períodos de tempo, que muitos não queriam ou não podiam despender. Como veremos à frente, a solução para este bloqueio laboral foi recorrer ao capital social para assim criar negócios por conta própria, estratégia frequentemente equacionada, pelos próprios, com uma maior e mais rápida acumulação de capital ( $v d$. também Salway 2008).

Em segundo lugar, para muitos, a chegada à Europa foi acompanhada por uma mobilidade profissional descendente, que se traduziu na aceitação de trabalhos em áreas do mercado de trabalho consideradas muito desprestigiantes. Com um perfil educacional relativamente elevado, finalistas do ensino secundário, licenciados e mesmo pós-graduados ( $v d$. Mapril 2008), os empregos a que tiveram acesso na Europa comportaram estigmas aos quais poucos se queriam ver associados. Alguns ainda tentaram ter acesso a posições no mercado de trabalho que correspondessem à sua formação académica, mas poucos, para não dizer nenhuns, foram bem sucedidos. As barreiras mencionadas pelos meus interlocutores incluem o desconhecimento da língua, o não reconhecimento dos diplomas ou a simples impossibilidade de acesso aos canais de divulgação.

Em terceiro lugar, muitos dos meus interlocutores têm parentes e amigos, tanto no Bangladeche como em Portugal, envolvidos em actividades empresariais e que servem de modelo e inspiração. Tornar-se um "patrão" é um indicador de êxito e de estatuto e, nessa medida, revela as percepções e ideologias face ao trabalho e ao emprego. Ser-se o próprio patrão é, pois, algo procurado activamente. Esta é uma aspiração que, apesar de estar já presente no Bangladeche, como mostrei noutro lugar (Mapril 2008), acaba por ser reforçada na migração perante a constatação de que os primeiros bangladechianos a chegar a Portugal são hoje proprietários de várias lojas e apresentam elevados níveis de riqueza. Estes exemplos revelam que prosperar não é continuar a trabalhar para outros, mas sim fazer um negócio e tornar-se um "patrão", um boss. É neste âmbito que circula e se reproduz uma percepção do trabalho e da participação na economia na qual os valores dominantes, para não dizer hegemónicos, remetem para uma ideia de êxito, cujo sinónimo é ter uma actividade por conta própria. Muitos acreditam que a acumulação de capital será tão rápida quanto mais depressa se investir num negócio por conta própria, o que, como veremos, nem sempre corresponde à realidade. 
Perante tal condição, muitos têm procurado investir na constituição de negócios, ainda que de pequena dimensão, o que está bem patente nas imediações da Praça Martim Moniz, no centro de Lisboa. É aqui que têm arrendado e comprado várias lojas e residências. De acordo com alguns relatos, será possível encontrar ali perto de mil bangladechianos, naquilo a que alguns dos meus interlocutores chamam uma banglapara. Para é uma expressão que remete para uma ideia de local de identificação, e bangla é o termo usado para o bengali; portanto, o Martim Moniz seria a "zona do bengali" ou a "zona para os bengaleses” (a designação é, aliás, usada para Lavapiés, em Madrid, onde se encontram muitos negócios bangladechianos).

Esta é uma área que poderia ser delimitada, ainda que com contornos imprecisos, a norte pelos Anjos, na Avenida Almirante Reis, a sul pelo Poço do Borratém e Rua da Betesga, a este pelo topo da Rua de São Lázaro e a oeste pelo final da Calçada dos Cavaleiros (em direcção à Graça). Aqui convivem fenómenos como procissões, imigração, comércio de revenda, toxicodependência, prostituição, "casas de produtos mágicos e feitiços de origem cultural múltipla" (Bastos 2001: 303), uma mesquita, um gurdwara (um templo sikh) e igrejas católicas e protestantes (evangélicos chineses).

O Martim Moniz, propriamente dito, é uma praça localizada nas imediações da baixa lisboeta, uma das principais zonas do centro histórico da capital, e o seu nome remete para a história da cidade, mais concretamente para o sacrifício de um capitão de D. Afonso Henriques, de nome Martim Moniz, aquando da tomada de Lisboa aos mouros, no século XII (Menezes 2004). ${ }^{6}$

\section{A PRAÇA MARTIM MONIZ EM LISBOA}

No panorama da capital, a Praça Martim Moniz faz a ligação entre a Avenida Almirante Reis e a Praça da Figueira e, como tal, é uma alternativa viária à Avenida da Liberdade, a principal artéria de acesso ao centro da cidade.

A área está, sobretudo, relacionada com o comércio grossista, ${ }^{7}$ e as lojas que se estendem nas artérias contíguas realçam esta relação. Nos dois lados da praça existem três centros comerciais - o Centro Comercial Martim Moniz, o Centro Comercial Grossista, também conhecido por Chinatown, e finalmente, o Centro Comercial Mouraria. Estas galerias vivem essencialmente da revenda de pronto-a-vestir, bricabraque e bijutaria, embora se encontrem também serviços tão variados como lojas de brinquedos, serviços de fotografia, sapateiros, ervanárias, vendas de objectos religiosos, agências de viagens,

6 Esta narrativa mítica é ainda hoje evocada na extremidade sul da praça com uma fonte que é também uma réplica da cerca moura.

7 Como vários autores salientam, o sector grossista tem uma enorme importância nesta zona da cidade, devido às próprias alterações e transformações históricas da capital (vd. Gaspar 1985; Vieira 1994; Malheiros 1996; Menezes 2004; Mapril 2001; inter alia). 
restaurantes, supermercados, lojas de coleccionismo, lojas de acessórios de telemóveis, papelarias, serviços de aluguer de DVD, vendas de cosméticos e lojas de mobiliário, actividades estas que mantêm evidentes continuidades nas principais vias adjacentes (ruas do Benformoso, de São Lázaro, João das Regras, da Mouraria, Calçada dos Cavaleiros, Poço do Borratém, expandindo-se mesmo para norte, em direcção à Praça do Chile, e a sul, para a "baixa pombalina").

Muitas lojas têm sido desenvolvidas não apenas por bangladechianos, mas também por indo-portugueses, guineenses, senegaleses, chineses e, mais recentemente, paquistaneses. Em 2003, durante o meu primeiro período de trabalho de campo, o panorama na zona era o seguinte:

\section{Quadro 1}

Presença comercial no Martim Moniz e zonas envolventes, 2003.

\begin{tabular}{|c|c|c|c|}
\hline $\begin{array}{l}\text { Origem nacional } \\
\text { dos ocupantes }\end{array}$ & $\begin{array}{l}\mathrm{N} .^{o} \\
\text { de lojas }\end{array}$ & $\begin{array}{l}\text { Tipo } \\
\text { de negócios }\end{array}$ & $\begin{array}{l}\text { Produtos } \\
\text { e serviços }\end{array}$ \\
\hline China & 129 & Grossistas/retalho & $\begin{array}{l}\text { Pronto-a-vestir (adulto), restauração, } \\
\text { supermercados, bricabraque, quinquilharias }\end{array}$ \\
\hline Bangladeche & 60 & Grossistas/retalho & $\begin{array}{l}\text { Pronto-a-vestir (criança, gangas), restauraçã } \\
\text { supermercados, bricabraque }\end{array}$ \\
\hline Indo-portugueses & 22 & Grossistas/retalho & $\begin{array}{l}\text { Pronto-a-vestir unisexo, bricabraque, } \\
\text { audiovisual, papelarias }\end{array}$ \\
\hline Paquistão & 10 & Grossistas/retalho & Restauração, bricabraque, audiovisual \\
\hline $\begin{array}{l}\text { Angola, Guiné, } \\
\text { Senegal e Zaire }\end{array}$ & 15 & Retalho & Cabeleireiros, supermercados, música, café \\
\hline
\end{tabular}

Levantamento feito pelo autor entre 1 e 9 de Janeiro de 2003 no âmbito do projecto "Imigrantes no Martim Moniz", Instituto de Ciências Sociais, coordenação de Cristiana Bastos.

Os indo-portugueses, hindus e muçulmanos, começaram a instalar-se na zona em meados dos anos 70, a seguir à descolonização, substituindo, na sua maioria, lojas de ramos de comércio tradicionais (alimentação, vestuário, casas de penhores, cafés/restaurantes), ou dedicando-se ao comércio de brinquedos, bijutarias, quinquilharias, mobiliário e à importação-exportação, sendo durante muito tempo os principais dinamizadores da área - em 1992, por exemplo, ocupavam um quarto das lojas do referido Centro Comercial Mouraria (Malheiros 1996; Marques e Ribeiro 1989; Vieira 1994; Ávila 1994). ${ }^{8}$

8 Actualmente, muitos têm arrendado ou mesmo vendido os anteriores espaços comerciais, para posterior conversão em imobiliário para arrendar. 
É em 1992 que guineenses, cabo-verdianos e, mais recentemente, senegaleses e zairenses abrem alguns negócios na zona, principalmente nas áreas da cosmética, música, produtos alimentares e restauração. No mesmo ano, a cave do Centro Comercial Mouraria estava quase totalmente ocupada por estes negócios e lojas (Malheiros 1996). Em 1993 surgiu a primeira loja de um comerciante chinês e três anos depois este mesmo centro comercial estava já maioritariamente ocupado por comerciantes chineses - principalmente provenientes da província de Zhejiang. Em 1996-97, aquele pioneiro chega a acordo com a administração do Centro Comercial Martim Moniz para explorar a respectiva cave, criando mais espaços comerciais grossistas. Como se pode ver pelo quadro acima, os chineses estavam, e ainda hoje estão, sobrerrepresentados na zona, sendo o grupo mais importante nas dinâmicas locais (Mapril 2001; Bastos 2004).

A acompanhar este estabelecimento comercial de chineses, começaram também a instalar-se paquistaneses e bangladechianos. Os primeiros dedicaram-se a negócios relativamente distintos dos anteriores, como é patente no quadro anterior. Os segundos, que mais interessam para o presente artigo, apostaram num tipo de negócios muito semelhante, ainda que com pequenas alterações, àquele desenvolvido pelos chineses. ${ }^{9}$

Segundo os meus interlocutores, foi em 1993 que o primeiro bangladechiano, natural da região de Sylhet, no noroeste do país, aqui se instalou, e foi por seu intermédio que a presença de bangladechianos se multiplicou. Em 2001, muitos começaram a arrendar algumas lojas na cave do Centro Comercial Martim Moniz, então explorada pela associação comercial Chinatown, e desde essa altura a sua presença tem aumentado de forma significativa.

Durante o primeiro período de trabalho de campo havia 60 lojas de bangladechianos nesta zona de Lisboa. Em 2006 eram já 80 ao longo da Avenida Almirante Reis, Rua da Palma, Calçada dos Cavaleiros, Rua do Benformoso, Largo do Intendente, Rua de São Lázaro e nos centros comerciais Mouraria e Martim Moniz. ${ }^{10}$ Em 2008, ocupavam já mais de 150 lojas, entre a Praça Martim Moniz e imediações, os Anjos e a baixa lisboeta (onde, só no último ano, abriram mais de 30 lojas). Actualmente, esta continua a ser vista como

9 Embora as semelhanças entre estes vários negócios sejam muito evidentes, existem subtis diferenças que parecem sugerir que este é um mercado crescentemente segmentado em termos de origens nacionais e tipo de produtos vendidos.

10 Os custos de arrendamento de todos estes negócios variam consideravelmente consoante a sua localização e área. As lojas no Centro Comercial Mouraria são das mais caras e são frequentemente subarrendadas - o valor da renda de uma loja é de 750 euros por mês, mas inclui a condição de o primeiro locatário ser sócio, uma vez que a chave da loja fica sempre com ele. Se o segundo locatário quiser ter a chave da loja, e portanto deixar de ter o sócio, então tem de pagar uma quantia significativa de trespasse, que pode ir até aos 35 mil euros. Pelas lojas que têm porta para a rua paga-se 750 e 1000 euros mensais, dependendo da área e da localização. 
uma zona ideal para fazer negócios, embora comecem a aparecer várias tentativas de diversificação e dispersão, devido à grande competição ali presente.

Segundo uma estimativa elaborada com base na observação das dinâmicas comerciais diárias, não parece ser incorrecto afirmar que, ao todo, estas lojas devem empregar perto de 300 pessoas, excluindo os proprietários. ${ }^{11}$ Estes são na maioria pioneiros, ou seja, aqueles que chegaram a Portugal no final dos anos 80 e inícios de 90, ou em 1996, aquando do primeiro e do segundo processos de regularização extraordinária, enquanto os empregados são quase sempre recém-chegados. É verdade que alguns negócios foram já constituídos por aqueles que chegaram durante o processo de regularização de 2001, mas estes representam uma pequena parcela do total e normalmente apenas têm uma loja, o que contrasta com muitos pioneiros que são proprietários de vários estabelecimentos. Um quarto das lojas existentes na zona do Martim Moniz pertencem a cinco dos mais antigos bangladechianos em Lisboa.

Os tipos de actividade económica desenvolvida estão intimamente ligados aos já praticados na zona, ao mesmo tempo que começam a surgir negócios especificamente direccionados para os bangladechianos e outros sul-asiáticos. Estes são de cinco diferentes tipos, de acordo com os produtos vendidos: (i) lojas de pronto-a-vestir; (ii) lojas de brinquedos e bricabraque; (iii) mercearias e supermercados; (iv) restaurantes; (v) diversos, incluindo papelarias, quiosques, etc.

As lojas de pronto-a-vestir, assim como os brinquedos e o bricabraque, encontram-se um pouco por todas as artérias e espaços comerciais da zona, mais concretamente nos centros comerciais Mouraria e Martim Moniz, na Rua do Benformoso, na Calçada dos Cavaleiros, na Rua de São Lázaro, na Rua da Palma, etc., e incluem roupas de homem, mulher e criança, frequentemente de marcas desconhecidas como Bou Bou, Ling, etc. As marcas das várias peças têm frequentemente nomes chineses e isso está ligado às próprias rotas de abastecimento usadas por muitos dos meus interlocutores ( $v d$. infra). Os principais clientes destas lojas são os revendedores que se dirigem semanalmente a esta zona para comprarem o que irão vender em mercados por todo o país, entre os quais se encontram populações ciganas. As compras são feitas por grosso e raramente são declaradas, o que, aliás, segundo alguns comerciantes, é precisamente o que torna estes negócios rentáveis.

Durante o último ano de trabalho de campo havia quatro supermercados/mercearias cujos proprietários eram bangladechianos. Três encontravam-se no exterior - dois na Rua do Benformoso e um na Calçada Cidadão João Gonçalves -, o quarto localiza-se na cave do Centro Comercial Mouraria. Parte dos produtos disponíveis são comuns às várias lojas do género, incluindo os restantes supermercados indianos nos centros comerciais Mouraria e Martim 
Moniz; no entanto, os quatro supermercados bangladechianos apresentam algumas especificidades (que desde logo os diferenciam da concorrência): dois estão vocacionados para um público mais generalista e, portanto, vendem de tudo, como qualquer mercearia, mas com alguns produtos regionais; um terceiro vende carne halal, ${ }^{12}$ enquanto outro se especializou na venda de peixe congelado com origem no Golfo de Bengala, onde é congelado e exportado para empresas especializadas no Reino Unido, para ser depois redistribuído. ${ }^{13}$

Em 2006 existiam nove restaurantes/cafetarias de bangladechianos na área metropolitana de Lisboa: dois na Costa da Caparica e sete no centro da cidade (quatro dos quais no Martim Moniz). Sete servem aquilo que convencionalmente se designaria por comida indiana e apenas ocasionalmente é possível encontrar alguns pratos, extramenu, mais próximos da cozinha do Bangladeche, tais como chawtpohtee (salada de grão com malaguetas, cebola, ovo e molho de tamarindo) ou mama-alim (sopa de grão com borrego). O facto de alguns dos restaurantes de cozinha indiana em Lisboa serem, na realidade, propriedade de bangladechianos, como aliás acontece no Reino Unido, está relacionado com a opinião generalizada de que um restaurante de cozinha indiana é um melhor negócio do que um restaurante bangladechiano, que seria um malogro (ainda assim, em dois casos existem referências evidentes à origem nacional do proprietário, através do uso de elementos decorativos associados ao Bangladeche). Um outro tipo de pronto-a-comer, o doner kebab, passou a ser também uma opção e, em 2006, dois dos meus interlocutores decidiram investir neste negócio depois de verem o sucesso de outras iniciativas similares desenvolvidas por paquistaneses. Tudo aquilo que se vende é halal, excepto as bebidas alcoólicas, e durante algumas festas do calendário anual preparam-se pratos normalmente associados a essas ocasióes. A clientela é maioritariamente não bangladechiana, ainda que alguns dos meus interlocutores, dada a proximidade física das suas lojas, recorram a estes estabelecimentos nos intervalos para almoço ou para beber um chá a meio da tarde.

Finalmente, há também uma papelaria e dois quiosques. É aqui que se enviam faxes para os países de origem, que se pede ajuda para traduzir e preencher formulários, que se fotocopia a documentação necessária para os processos de legalização, que se imprime e vende uma edição do Daily Jugantor (uma versão impressa da edição online de um diário bangladechiano) e, por fim, que circulam novidades e informações acerca das oportunidades existentes (de empregos, legalização, entre outras). Neste caso, a venda de jornais, de tabaco, de postais e de algum material de papelaria tem clientes

12 Halal remete para a ideia de lícito, permitido, autorizado e, neste caso, está associado à forma como o animal é abatido (realiza-se um acto ritual através do qual o animal é sangrado).

13 Contrariamente ao que acontece nas lojas de roupa, onde não há quaisquer referências etnicizadas, no caso das mercearias passa-se precisamente o oposto. 
indiferenciados, à excepção dos cartões de telefone, que têm nos estrangeiros a clientela primordial. A papelaria tem como clientes principais bangladechianos e outros sul-asiáticos.

Depois desta breve descrição da configuração da banglapara, é indispensável perceber que o êxito destas iniciativas depende de um delicado equilíbrio entre actividades económicas formais e informais; isto é visível tanto nas estratégias para angariar o capital inicial quanto nas próprias estruturas dos negócios.

\section{ENTRE O FORMAL E O INFORMAL}

Como acontece noutros exemplos descritos na literatura, também aqui podemos verificar que todas estas actividades dependem largamente das redes sociais e relações de confiança para se desenvolverem e serem bem sucedidas. É graças a várias sociabilidades, assentes no parentesco, na amizade, na "comunidade" e mesmo fora dela, que muitos bangladechianos acedem a recursos económicos, know-how, recursos humanos, informações, etc., indispensáveis à apropriação das oportunidades existentes (Waldinger, Aldrich e Ward 1990; Waldinger 1989 e 1996; Granovetter 1995; Portes 1999; Yanagisako 2002; Lima 2002; Narotzky e Smith 2006). Como no caso de outros sul-asiáticos (Werbner 1990; Anwar 1995; Goody 2000), também entre os bangladechianos em Lisboa estas redes e sociabilidades incluem parentes paternos (membros da unidade doméstica e da patrilinhagem), parentes maternos e descendentes. Mesmo amizades desenvolvidas ainda no Bangladeche (ao nível da vizinhança, da frequência de uma mesma escola) ou relações já estabelecidas no estrangeiro são indispensáveis em todo este processo. ${ }^{14}$ Revelador desta importância é o facto de frequentemente as pessoas se tratarem por designações de parentesco como bhai (irmão), chacha (tio paterno) ou mama (tio materno), mesmo quando não são aparentadas entre si por laços de consanguinidade ou de aliança (o que formalmente implica, desde logo, obrigações e deveres recíprocos).

No entanto, nalguns contextos estas sociabilidades incluem não bangladechianos. No contexto comercial, as relações com chineses, paquistaneses, portugueses, ucranianos, entre outros, são mantidas e mesmo fomentadas (noutras arenas da vida social, tais laços e contactos são diminutos e por vezes mesmo evitados).

Todas estas sociabilidades são indispensáveis, pois, como já foi aflorado, permitem angariar capital económico, obter informações acerca dos mercados a explorar, de fornecedores, de empregados, treino na actividade, etc. Além

14 Estas redes assemelham-se às descritas por Mayer (1966) quando falava de quasi-grupos de parentesco. Também estes se baseiam numa obrigação moral activada por um elemento da rede e a sua constituição inclui parentes cognáticos e por afinidade, bem como amizades. É, portanto, na parentela que se encontra a base principal de recrutamento para o grupo de acção. 
disto, e como veremos à frente, os próprios parentes (atyio) são capital humano para o apoio às actividades comerciais.

No que diz respeito ao capital inicial, foi possível constatar que uma parte é constituída por poupanças individuais resultantes do trabalho por conta de outrem; no entanto, e como vimos anteriormente, para aqueles que permanecem em Portugal, é extremamente difícil realizar estas poupanças, devido aos baixos salários e às despesas diárias. ${ }^{15}$ Uma das soluções passa por trabalhar algumas temporadas noutros países, onde os salários são mais elevados, e posteriormente regressar a Portugal para investir num negócio. Outra estratégia é, como veremos à frente, a venda ambulante em feiras, nacionais e regionais, ou mesmo nas zonas turísticas das cidades.

Para além destas iniciativas de acumulação de capital, muitos dos meus interlocutores contraíram empréstimos, tanto no âmbito da unidade doméstica como entre amigos e conhecidos. No primeiro caso, é frequente ver alguns destes negócios serem parcialmente financiados com a ajuda dos pais e dos irmãos que se encontram no Bangladeche e noutros locais. Na ausência de capital económico disponível, uma das estratégias é vender propriedades no Bangladeche e depois transferir a respectiva verba para Lisboa através de amigos e conhecidos. Esta conversão de capital é no entanto problemática e para que seja realizada são necessárias negociações sensíveis com os membros da família. A terra é um recurso valioso e, como tal, apenas em última instância e na ausência de alternativas deve ser vendida, como muitos dos meus interlocutores tantas vezes me relataram. Se não houver retorno, tal conversão pode levar uma unidade doméstica à ruína.

Outra alternativa de financiamento é contrair empréstimos junto de amigos e conhecidos em Portugal e no Bangladeche, ou então recorrer a associações regionais de natureza informal que, entre outras actividades, facilitam o crédito com a garantia de que os reembolsos serão realizados atempadamente (a proximidade geográfica no país de origem é o garante da seriedade no cumprimento das obrigações).

Uma outra solução para a obtenção de financiamento consiste em recorrer a um intermediário português que circula diariamente pela zona. Estes empréstimos são contraídos tanto por bangladechianos como por chineses e os pagamentos são normalmente realizados semanalmente, em pequenas parcelas recolhidas pelo próprio. A garantia de pagamento reside no facto de quase todos já terem usufruído destes serviços e, portanto, protegerem a continuação deste sistema através da condenação social dos faltosos. A coacção

15 O capital económico necessário para iniciar muitos destes negócios varia consoante aquilo que se quer fazer. Segundo os meus interlocutores, um restaurante é muito mais dispendioso do que abrir uma pequena loja de pronto-a-vestir, de venda por grosso, nas artérias centrais da Mouraria. 
é socialmente imposta e assim os custos associados à falta de pagamento de dívidas são demasiado elevados para o infractor.

Finalmente, uma outra forma de obter os necessários financiamentos é através de empréstimos bancários. No caso dos bangladechianos com cidadania portuguesa, os trâmites seguidos são iguais aos aplicáveis aos restantes cidadãos nacionais, mas no caso de portadores de autorizações de permanência a única possibilidade é apresentar um fiador, que terá de ser, necessariamente, um cidadão português. Nestes casos, os pioneiros são, por vezes, solicitados para esse fim, mas evidentemente nem sempre com sucesso. A aceitação acarreta evidentes riscos e apenas em circunstâncias de grande proximidade e confiança é comum que aceitem.

Ao longo do trabalho de campo verifiquei que o recurso aos serviços bancários era mais frequente entre os pioneiros, precisamente porque tinham os documentos necessários e apresentavam recursos - lojas, casas, carros - que funcionavam como garantias para as entidades bancárias. Com estes empréstimos procuravam injectar capital nos negócios que já possuíam, criar novos, ou então fazer viagens de prospecção comercial em busca de novos fornecedores.

Ao nível da estrutura, muitos destes negócios e lojas estão normalmente registados por empresas em nome individual e não é de todo incaracterístico estas terem mais de uma loja a elas associada. Estas podem ser todas exploradas pela pessoa no nome da qual a empresa está registada, ou então por outros que, por questões várias, nomeadamente a ausência dos documentos necessários, não podem registar uma empresa em seu nome mas que conseguem reunir os recursos necessários para ter um estabelecimento. Nestes casos, os interessados pedem a quem já tem empresas para registar a loja e posteriormente, quando já podem constituir uma empresa, transferem então o registo.

Existem igualmente sociedades informais, no âmbito das quais as lojas são registadas apenas no nome de um dos sócios. Num dos casos estudados, uma das partes pagava a renda enquanto a outra dava o trabalho e comprava as mercadorias. No entanto, como estas situações ocorrem apenas quando existe algum grau de proximidade entre as partes, não são muito frequentes. A desconfiança é grande e muitos consideram as sociedades uma iniciativa arriscada. Nos casos em que as sociedades se efectivam, surgem por vezes conflitos entre as partes, que levam à dissolução das mesmas. Estas negociações são mediadas por um terceiro elemento, tal como acordado previamente entre os sócios, normalmente alguém respeitado e com mais experiência. Quer seja na divisão dos lucros quer nas compensações a pagar, é frequente o recurso a tais intermediações. Este processo é comummente designado pelo termo samaj, ${ }^{16}$

16 De uma forma algo simplista e apenas para efeitos de esclarecimento, samaj (também conhecida por reyia) é um termo cuja origem reside na noção de "fazer em conjunto". No quotidiano tem vários significados e pode ser traduzido como "sociedade" ou "associação" e frequentemente [continua] 
cujo significado literal é "sociedade", e que tem como intuito impedir, o mais possível, a intervenção externa.

Mesmo no caso do recrutamento dos empregados, o encastramento das actividades económicas nos laços sociais é evidente. A maior parte das lojas de pronto-a-vestir têm pelo menos um empregado a quem é atribuída a responsabilidade por todas as tarefas - as vendas, o descarregamento das mercadorias, o acondicionamento das mesmas, etc. A escolha dos empregados é feita com base nas redes de relações sociais do patrão. Quase todos os trabalhadores alcançaram estes empregos porque foram recomendados. É raro encontrar não bangladechianos a trabalhar em lojas bangladechianas, o que indica que os laços de vizinhança, de pertença a uma mesma unidade doméstica, regionais, nacionais, etc. são instrumentalizados para manter estes postos de trabalho encerrados ao exterior. $\mathrm{O}$ caso dos restaurantes, porém, apresenta algumas especificidades, pois é comum os empregados serem não só bangladechianos, mas também paquistaneses e indianos - quem serve às mesas são quase sempre os primeiros, e quem cozinha são quase sempre os segundos e os terceiros.

Noutros casos, o empregado é parente do patrão, opção que tem assumido uma crescente importância apenas nos últimos anos, devido aos processos de reunificação familiar. Nalgumas lojas é frequente encontrar um irmão do proprietário ou da esposa e os filhos, mais concretamente durante as férias escolares e as horas livres. É também comum encontrar as esposas a trabalhar nas lojas pertencentes à unidade doméstica, em substituição do marido, a ajudar na gestão de mais do que um negócio ou simplesmente a trabalhar a partir de casa ( $v d$. Kabeer 2000).

No caso dos familiares, não é frequente receberem um salário, uma vez que se assume que se está a trabalhar para a mesma unidade doméstica. Isto é muitas vezes contrabalançado com a ideia de que o familiar não recebe agora para receber o apoio financeiro do parente mais tarde, quando quiser fazer algum investimento. No caso dos empregados não familiares, os salários nem sempre incluem os pagamentos à Segurança Social e são muitas vezes os empregados que devem fazê-lo, retirando a percentagem do respectivo ordenado. Estes oscilam entre os 350 euros e o máximo de 800 euros. O mais frequente, porém, é o salário mensal (do qual tem de se retirar a percentagem da contribuição para a Segurança Social) situar-se entre os 500 e os 600 euros mensais. ${ }^{17}$ Como

[continuação] significa a comunidade a que se pertence e que está para além da família e da patrilinhagem. Os seus limites territoriais são normalmente coincidentes com os limites da mais pequena unidade administrativa (equiparável a uma freguesia), a para. Num sentido estrito, a samaj é uma assembleia de anciãos, para a qual todas as patrilinhagens da para devem contribuir com um membro e cuja função é manter e estabelecer a ordem entre os membros (para um maior aprofundamento, vd. Kotalová 1993, inter alia).

17 Como acontece noutros casos ( $v d$. Anthias 1983; Cook 1984; Bonacich 1993), verifica-se uma elevada marginalização da mão-de-obra empregada, com baixos salários, horas extraordinárias [continua] 
complemento a estes rendimentos, muitos empregados recorrem à venda ambulante, mais concretamente ao fim-de-semana, em feiras, pequenos mercados ou nas ruas das principais cidades (especialmente em zonas turísticas). Aqui vendem-se produtos comprados aos próprios patrões e entre as mercadorias encontram-se bens contrafeitos, flores, pequena bijutaria e mesmo decorações de Natal.

Também ao nível dos abastecedores se fica ciente de que é no âmbito de diversas relações sociais que se tem acesso às várias mercadorias. Nas lojas de roupa, por exemplo, quando os primeiros bangladechianos se instalaram e como não tinham acesso a fornecedores, recorreu-se a comerciantes chineses para a compra de mercadorias. Actualmente, estas redes continuam a ser mantidas e muitos socorrem-se destes contactos com chineses para se abastecer.

Devido a esta relação entre bangladechianos e chineses, ainda se nota um outro pormenor no tipo de mercadorias vendidas. Comparando com as lojas chinesas, não é incorrecto afirmar que as lojas bangladechianas vendem mais gangas e roupa para criança, o que se deve, segundo dados recolhidos no terreno, a um acordo informal para diminuir a competição entre bangladechianos e chineses. Isto tem permitido a muitos dos meus interlocutores manterem os seus negócios, já que, como muitos dizem, "é impossível competir com os chineses". Outra das estratégias passa pela diversificação dos fornecedores e produtos. A venda de roupa como fátuas e punjabis, que, segundo os meus interlocutores, são essencialmente usadas por sul-asiáticos, bem como o recurso a bens contrafeitos (pronto-a-vestir, DVD ou CD) são alguns exemplos emblemáticos.

Finalmente, o abastecimento dos quiosques inclui soluções diferenciadas consoante os produtos em causa. À excepção dos cartões telefónicos, os produtos são todos abastecidos por portugueses, o que implica estratégias formais e informais de distribuição. Por exemplo, o arrendatário de um dos quiosques encomenda os jornais para em seguida os redistribuir junto daqueles que não têm capital suficiente para pagar a caução exigida pelos distribuidores de jornais e revistas.

Através desta descrição ficamos cientes de que estas práticas empresariais dependem das redes de relações sociais, redes essas que estão inscritas em várias escalas - a unidade doméstica, a patrilinhagem, a região, a co-nacionalidade,

nem sempre pagas, etc. Tal cenário implica uma forte diferenciação social de classe, onde o sucesso empresarial de pioneiros e patrões depende da contínua exploração dos empregados e bangladechianos mais recém-chegados. Nestes casos, os empregados procuram criar os seus próprios negócios e assim autonomizar-se face aos empregadores, caso contrário podem ver a sua dependência perpetuar-se no tempo. Poder-se-ia argumentar, como muitos dos meus interlocutores fazem, que trabalhar para outros conterrâneos nem sempre é garante de mobilidade social, antes pelo contrário. Alguns preferem trabalhar fora destas redes precisamente para escapar a tais dinâmicas e processos, onde o controlo social impede qualquer possibilidade de negociação. 
e mesmo a transnacionalidade. Sem estas práticas, seria impossível realizar tais empreendimentos. Mais, muitas estratégias referidas encontram-se, obviamente, e de acordo com os modelos normativos da economia, no âmbito da informalidade. No entanto, sem elas, muito dificilmente os negócios conseguiriam prosperar.

\section{REFLEXÕES FINAIS}

Ao longo deste artigo mostrei que, desde a chegada a Portugal, muitos bangladechianos desenvolvem actividades económicas que se encontram entre o formal e o informal. Inicialmente, apenas conseguem aceder a posições socioeconómicas marginais, onde começam por trabalhar nos sectores mais desprivilegiados, em actividades que jamais executariam no Bangladeche. Estas são marcadas por uma enorme informalidade, onde os trabalhadores não têm contratos de trabalho e os rendimentos não são declarados. Por vezes, trabalhar para um conterrâneo também não é o garante de mobilidade social, bem pelo contrário. Um primeiro passo para sair desta marginalidade é procurar investir num negócio e, para o conseguir, recorre-se ao próprio capital social, com o objectivo de desenvolver pequenas actividades comerciais, muitas vezes marcadas por baixos valores de entrada. Nestes mercados, tem de se fazer face a uma enorme competição, o que direcciona muitos a manterem-se na intersticialidade entre as economias formal e informal, sem a qual não é possível realizar a desejada acumulação de capital.

Mas será este um cenário exclusivo dos bangladechianos? E apenas de Portugal? Em ambos os casos, a resposta é evidentemente negativa, já que o recurso a estratégias informais parece ser bem mais generalizado e simultaneamente presente em muitos e diferentes contextos nacionais. Em relação à primeira questão, basta um olhar histórico sobre o Martim Moniz e zonas envolventes para perceber como muitas destas dinâmicas são levadas a cabo por muitos, tanto "imigrantes" como "autóctones". Esta zona da cidade de Lisboa parece "falar" de algo muito mais vasto e complexo: a importância da informalidade na economia nacional. Em Portugal, calcula-se que as actividades informais representem (dados de 2006) entre 22\% e 25\% do Produto Interno Bruto (Antunes e Cavalcanti 2006). Os sectores de trabalho onde aparecem mais frequentemente são a construção civil e as actividades comerciais ligadas à hotelaria e aos serviços domésticos, o que já ocorria muito antes dos fluxos migratórios dos últimos trinta anos (Cabral 1983). Ora, de acordo com os dados apresentados por Baganha $(1998,2000)$, é precisamente para estes sectores que os imigrantes vão ser canalizados e o caso dos serviços, mais concretamente do pequeno comércio a retalho e grossista, é exemplificativo. Estes espaços do mercado de trabalho têm vindo a ser apropriados por várias vagas de (i)migrantes desde meados dos anos 70, uma vez que estes negócios 
de pequena dimensão se constituem, por vezes, como o único espaço a que conseguem aceder no mercado de trabalho.

Mas esta relação entre sectores desvalorizados do mercado de trabalho, actividades informais e imigração é comum a outros contextos e, embora não disponha de dados a nível global, vários estudos indiciam esta estreita relação. Tanto na Europa do Sul como em Nova Iorque, Londres ou Paris, muitos dos fluxos globais de migrantes laborais contemporâneos estão de alguma forma ligados a "espaços" do mercado de trabalho onde a informalidade apresenta uma importância central (Mingione e Quassoli 2000; King, Lazaridis e Tsardanidis 2000; Baganha, Malheiros e Ferrão 1999; Marques, Santos e Araújo 2001; Grassi 2003; Sassen-Koob 1989; Sassen 1998). Stepick (1989), por exemplo, explora o papel que a economia informal desempenha junto de haitianos em Miami, onde a reparação de automóveis e os restaurantes não licenciados são algumas das actividades desenvolvidas para escapar à pobreza. MacGafey e Bazenguissa-Ganga (2000) mostram como os imigrantes, os estudantes e os ex-funcionários do governo congolês participam numa economia paralela que se espraia entre Paris e o Congo. Mais recentemente, Stoller (2002) revelou como comerciantes oriundos da África Ocidental em Nova Iorque entraram no chamado sector informal como vendedores ambulantes, não registados, de bens contrafeitos e "pirateados".

Poderia mencionar outros exemplos, mas o que importa aqui realçar é o facto de encontrarmos cenários semelhantes ao descrito anteriormente em locais tão diferentes como Nova Iorque, Miami ou Paris, o que obviamente levanta a hipótese de que a informalidade está, de alguma forma, relacionada com uma condição estrutural (Portes e Sassen-Koob 1987). Tal constatação leva-me a concordar com Sassen (1991) quando argumenta que a economia informal é o resultado, antes de mais, de factores sistémicos. Os reajustamentos económicos globais, baseados na descentralização da produção, no trabalho flexível e na subcontratação afectaram vários países através da crescente informalização das economias (Portes e Sassen-Koob 1987; Coombe e Stoller 1994). A sua presença, crescimento e importância em cidades tão diferentes como Nova Iorque, Lisboa ou Acra indiciam a relação entre a informalização do trabalho e as condições criadas pelo capitalismo tardio a nível global (Sassen 1991). Isto parece ser verdade, não apenas para os sectores mais desprivilegiados do mercado de trabalho, mas também para os potenciais negócios desenvolvidos por imigrantes.

O que tal fenómeno implica é que este crescimento da informalidade foi evidentemente acompanhado pelo recrutamento de determinados segmentos sociais, entre os quais se incluem populações ditas autóctones, tais como jovens, mulheres, idosos e filhos de imigrantes, mas também migrantes internacionais.

Antes de terminar, gostaria de salientar que, obviamente, as iniciativas empresariais protagonizadas por imigrantes podem ser de facto sinais de êxitos 
e sucesso na integração no mercado de trabalho. Existem muitos casos que corroboram tais interpretações. No entanto, este fenómeno apresenta uma outra face, por vezes silenciada, que se relaciona com o facto de estas iniciativas resultarem de - e/ou produzirem - processos de marginalização. Escamotear este último elemento é reproduzir de forma acrítica os modelos económicos dominantes globais, mas, mais importante ainda, é colocar na penumbra os processos de marginalização que "empurram" alguns segmentos da população, "imigrantes" e "autóctones", para actividades económicas que apenas podem ser bem sucedidas recorrendo a práticas ditas informais.

\section{BIBLIOGRAFIA}

ANTHIAS, Floya, 1983, "Sexual divisions and ethnic adaptation: the case of Greek-Cypriot women”, em Annie Phizacklea (org.), One Way Ticket: Migration and Female Labour. Londres, Routledge and Kegan Paul, 73-94.

ANTUNES, António, e Tiago CAVALCANTI, 2006, "Custos de legalização, cumprimento de contratos e o sector informal”, Boletim Económico, 12 (1): 69-80.

ANWAR, Muhammad, 1995, "Social networks of Pakistanis in the UK: A re-evaluation", em Alisdair Rogers e Steven Vertovec (orgs.), The Urban Context: Ethnicity, Social Networks and Situational Analysis. Oxford, Berg Publishers, 237-257.

ÁVILA, Patrícia, 1994, "Indianos comerciantes na cidade de Lisboa", comunicação apresentada no Colóquio "Minorias Étnicas: A Participação na Vida da Cidade”, Conselho Municipal das Comunidades Imigrantes e das Minorias Étnicas do Concelho de Lisboa.

BAGANHA, Maria, 1998, "Immigrant involvement in the informal economy: the portuguese", Journal of Ethnic and Migration Studies, 24 (2): 367-385.

— 2000, "Labour market and immigration: economic opportunities for immigrants in Portugal”, em Russel King, Gabriella Lazaridis e Tsardanidis Charalambos (orgs.), Eldorado or Fortress? Migration in Southern Europe. Londres, Macmillan Press, 79-103.

BAGANHA, Maria, Jorge MALHEIROS, e João FERRÃO, 1999, “Os imigrantes e o mercado de trabalho: o caso português”, Análise Social, 150: 147-173.

BASTOS, Cristiana, 2001, "Omulu em Lisboa: etnografias para uma teoria da globalização", Etnográfica, 5 (2): 303-334.

—, 2004, "Lisboa, século XXI: uma pós-metrópole nos trânsitos mundiais", em José Machado Pais e Leila Blass (orgs.), Tribos Urbanas: Produção Artística e Identidades. Lisboa, Imprensa de Ciências Sociais, 195-224.

BONACICH, Edna, 1987, "Making it in America: a social evaluation of the ethics of immigrant entrepreneurship", Sociological Perspectives, 30 (4): 446-466.

— 1993, "The other side of ethnic entrepreneurship: a dialogue with Waldinger, Aldrich, Ward and Associates", International Migration Review, 27 (3): 685-692. 
CABRAL, Manuel Villaverde, 1983, "A economia subterrânea vem ao de cima: estratégias rurais perante a industrialização e a urbanização”, Análise Social, 19: 199-234.

COOK, Scott, 1984, "Peasant economy, rural industry and capitalist development in the Oaxaca valley, México", Journal of Peasant Studies, 12 (1): 3-40.

COOMBE, Rosemary, e Paul STOLLER, 1994, "X Marks the spot: the ambiguities of African trading in the commerce of the Black public sphere", Public Culture, 15: 249-275.

CUNHA, Manuela Ivone, 2006, "Formalidade e informalidade: questões e perspectivas", Etnográfica, 10 (2): 219-231.

GASPAR, Jorge, 1985, A Dinâmica Funcional do Centro de Lisboa. Lisboa, Livros Horizonte.

GÓIS, Pedro, 2006, A Emigração Cabo-Verdiana para (e na) Europa e a Sua Inserção em Mercados de Trabalho Locais: Lisboa, Milão, Roterdão. Lisboa, ACIME.

GOODY, Jack, 2000, O Oriente no Ocidente. Lisboa, Difel.

GRANOVETTER, Mark, 1995, “The economic sociology of firms and entrepreneurs", em Alejandro Portes (org.), The Economic Sociology of Immigration: Essays on Networks, Ethnicity, and Entrepreneurship. Nova Iorque, Russel Sage Foundation, 128-163.

GRASSI, Marzia, 2003, Rabidantes: Comércio Espontâneo Transnacional em Cabo Verde. Lisboa, Imprensa de Ciências Sociais.

HART, Keith, 1973, "Informal income opportunities and urban employment in Ghana", The Journal of Modern African Studies, 11 (1): 61-89.

KAABER, Naila, 2000, The Power to Choose: Bangladeshi Women and Labour Market Decisions in London and Dhaka. Londres, Verso.

KING, Russel, Gabriela LAZARIDIS, e Charalambos TSARDANIDIS (orgs.), 2000, Eldorado or Fortress? Migration in Southern Europe. Londres, Macmillan Press.

KLOOSTERMAN, Robert, e Jan RATH, 2001, "Immigrant entrepreneurs in advanced economies: mixed embeddedness further explored”, Journal of Ethnic and Migration Studies, 27 (2): 189-201.

KLOOSTERMAN, Robert, J. VAN DER LEUN, e Jan RATH, 1999, “Mixed embeddedness: informal economic activities and immigrant business in the Netherlands", International Journal of Urban and Regional Research, 23 (2): 253-267.

KOTALOVÁ, Jitka, 1993, Belonging to Other: Cultural Construction of Womenhood in a Village in Bangladesh. Daca, University Press Limited.

LIMA, Antónia Pedroso de, 2002, Grandes Famílias, Grandes Empresas: Ensaio Antropológico sobre a Elite de Lisboa. Lisboa, Dom Quixote.

MACGAFFEY, Janet, e Remy BAZENGUISSA-GANGA, 2000, Congo-Paris: Transnational Traders on the Margins of the Law. Londres, James Currey.

MACHADO, Fernando, 2002, Contrastes e Continuidades: Migração, Etnicidades e Integração dos Guineenses em Portugal. Oeiras, Celta Editora.

MALHEIROS, Jorge, 1996, Imigrantes na Região de Lisboa: Os Anos da Mudança. Lisboa, Edições Colibri.

—, 2001, Arquipélagos Migratórios: Transnacionalismo e Inovação. Lisboa, Universidade de Lisboa, tese de doutoramento.

MAPRIL, José, 2001, “De Wenzhou ao Martim Moniz: práticas diaspóricas e (re)negociação identitária do local”, Ethnologia, 12-14: 253-294.

—, 2008, "Os sonhos da 'modernidade': migrações globais, e consumos entre Lisboa e Dhaka”, em Renato Carmo, Ruy Blanes e Daniel Melo (orgs.), A Globalização no Divã. Lisboa, Tinta da China, 65-88. 
MARQUES, Filomena, e Manuel RIBEIRO, 1989, Alfama e Mouraria: Caracterização Sociológica $e$ do Edificado. Lisboa, Câmara Municipal de Lisboa.

MARQUES, Margarida, e Nuno DIAS, 2005, Immigrant Entrepreneurs in Portugal: Three Stories on Embedded Autonomy. Lisboa, SociNova Working Papers.

MARQUES, Margarida, Rui SANTOS, e Fernanda ARAÚJO, 2001, "Ariadne's thread: Cape Verdean women in transnational webs", Global Networks, 1 (3): 283-306.

MAYER, Adrian, 1966, "The significance of quasi-groups in the study of complex societies", em Michael Banton (org.), The Social Anthropology of Complex Societies. Londres, Tavistock Publications, 97-122.

MENEZES, Marlucci, 2004, Mouraria: Retalhos de um Imaginário. Oeiras, Celta Editora.

MINGIONE, Enzo, e Fábio QUASSOLI, 2000, "The participation of immigrants in the underground economy in Italy”, em Russel King, Gabriella Lazaridis e Charalambos Tsardanidis (orgs.), Eldorado or Fortress? Migration in Southern Europe. Londres, Macmillan Press, 27-56.

NAROTZKY, Susana, e Gavin SMITH, 2006, Immediate Struggles: People, Power and Place in Rural Spain. Berkeley, University of California Press.

OLIVEIRA, Catarina, 2005, Empresários de Origem Imigrante: Estratégias de Inserção Económica em Portugal. Lisboa, ACIME.

OLIVEIRA, Catarina, e Jan RATH, 2008, "Introdução" do número temático sobre empreendedorismo imigrante, Revista Migrações, 3: 11-28.

PORTES, Alejandro, 1999, Migrações Internacionais: Dos Factos aos Conceitos. Oeiras, Celta Editora.

PORTES, Alejandro, e Manuel CASTELLS, 1989, "World underneath: the origins, dynamics and effects of the informal economy", em Alejandro Portes, Manuel Castells e Lauren Benton (orgs.), The Informal Economy: Studies in Advanced and Less Developed Countries. Baltimore e Londres, Johns Hopkins University, 1 1-40.

PORTES, Alejandro, e Saskia SASSEN-KOOB, 1987, "Making it undergound: comparative material on the informal sector in Western market economies", American Journal of Sociology, 93 (1): 30-61.

RATH, Jan, 2000, "Introduction: immigrant businesses and their economic, politico-institutional and social environment", em Jan Rath (org.), Immigrant Businesses: The Economic, Political and Social Environment, Londres, Macmillan Press, 1-19.

SALWAY, Sarah, 2008, "Labour market experiences of young UK Bangladeshi men: identity, inclusion, exclusion in inner-city London", Ethnic and Racial Studies, 31 (6): 1126 $-1152$.

SASSEN, Saskia, 1991, The Global City: New York, London, Tokyo. Princeton, Princeton University Press.

—, 1998, Globalization and its Discontents. Nova Iorque, The New Press.

SASSEN-KOOB, Saskia, 1989, "New York city's informal economy”, em Alejandro Portes, Manuel Castells e Lauren Benton (orgs.), The Informal Economy: Studies in Advanced and Less Developed Countries. Baltimore e Londres, Johns Hopkins University, 60-77.

STEPICK, Alex, 1989, "Miami’s two informal sectors”, em Alejandro Portes, Manuel Castells e Lauren Benton (orgs.), The Informal Economy: Studies in Advanced and Less Developed Countries. Baltimore, Johns Hopkins University Press, 11 1-134.

STOLler, Paul, 2002, Money Has no Smell: The Africanization of New York City. Chicago, Chicago University Press. 
VIEIRA, Clara, 1994, "Um bairro em recuperação: a Mouraria de Lisboa”, Ler História, 26 : 206-210.

WALDINGER, Roger, 1989, "Structural opportunity or ethnic advantage? Immigrant business development in New York”, International Migration Review, 23 (1): 48-72.

_., 1996, Still the Promised City? Cambridge, MA, Harvard University Press.

WALDINGER, Roger, Howard ALDRICH, e Robin WARD (orgs.), 1990, Ethnic Entrepreneurs: Immigrant Business in Industrial Societies. Newbury Park, CA, Sage Publications.

WERBNER, Pnina, 1990, The Migration Process: Capital, Gifts and Offerings among British Pakistanis. Londres, Berg Publishers.

YANAGISAKO, Sylvia, 2002, Producing Culture and Capital: Family Firms in Italy. Princeton, Princeton University Press.

Banglapara: immigration, businesses and (in)formalities in Lisbon - José Mapril - CRIA/ /ISCTE-IUL, Portugal • jmapril@gmail.com

In recent years, migration studies dedicated part of their interest to entrepreneurial activities. Opportunity structures and social capital are two dimensions frequently mentioned to explain the emergence of such initiatives. A third dimension, though, is the relation between immigration and what has been frequently described as "underground", "subterranean", "parallel" or simply "informal" economies. This is precisely the main theme of the present article. Based on a case study about Bangladeshis in Lisbon, my objective is to show how the success of small-scale entrepreneurial activities depends on strategies that are located between the formal and informal sides of the economy.

KEYWORDS: informality, entrepreneurs, immigration, Lisbon, Bangladeshis, Southern Europe. 